\title{
Prevalence and risk factors for exposure to Toxoplasma gondii in slaughterhouse workers in western Kenya
}

Elizabeth Anne Jessie Cook ${ }^{1,2^{*}}$, Nduhiu Gitahi ${ }^{3 \dagger}$, William Anson de Glanville ${ }^{1,4}$, Lian F. Thomas ${ }^{1,2}$, Samuel Kariuki ${ }^{5}$, Erastus Kang'ethe ${ }^{3}$ and Eric Maurice Fèvre ${ }^{1,2}$

\begin{abstract}
Background: Toxoplasma gondii is a zoonotic protozoan parasite infecting warm-blooded animals. Infection in people can occur through ingestion of oocysts passed in the faeces of the definitive hosts; ingestion of bradyzoites in the tissue of infected intermediate hosts; or exposure to tachyzoites in raw milk and eggs. Slaughterhouse workers are considered a high-risk group for T. gondii exposure because of their contact with raw meat, although a positive relationship between handling raw meat and T. gondii seropositivity has not been demonstrated in all studies. This study aimed to determine the seroprevalence of antibodies to T. gondii in slaughterhouse workers in Kenya and identify risk factors associated with seropositivity.
\end{abstract}

Methods: A survey of slaughterhouse workers was conducted in 142 slaughter facilities in the study area. Information regarding demographics, contact with livestock, meat consumption, and practices in the slaughterhouse was collected using structured questionnaires. Commercial ELISAs were used to detect IgM and IgG antibodies against $T$. gondii and a multi-level logistic regression model was used to identify potential risk factors for seropositivity in slaughterhouse workers.

Results: The apparent prevalence of antibodies to T. gondii was 84.0\% (95\% Confidence Interval (Cl) 81.2-86.5\%) for IgG and 2.2\% (95\% Cl 1.3-3.5\%) for IgM antibodies. All IgM positive individuals were IgG positive. Risk factors for exposure to T. gondii were: increasing age (Odds Ratio (OR) 1.03; 95\% Cl 1.01-1.05); owning poultry (OR 2.00; $95 \% \mathrm{Cl}$ 1.11-3.62); and consuming animal blood (OR 1.92; 95\% Cl 1.21-3.03).

Conclusions: The seroprevalence of antibodies to T. gondii was very high in this population and considerably higher than published values in the general population. Risk factors included age, owning poultry and drinking animal blood which were consistent with previous reports but none were specifically associated with working in the slaughterhouse. In this instance slaughterhouse workers may represent a useful sentinel for the general population where the level of exposure is also likely to be high and may signify an unidentified public health risk to vulnerable groups such as pregnant women. A detailed understanding of the epidemiology of infection is required, which should include an assessment of incidence, mortality, and burden since T. gondii infection is likely to have life-long sequelae.

\footnotetext{
*Correspondence: e.cook@cgiar.org

†Elizabeth Anne Jessie Cook and Nduhiu Gitahi contributed equally to this work

${ }^{1}$ International Livestock Research Institute, Old Naivasha Road, P.O.

Box 30709, Nairobi 00100, Kenya

Full list of author information is available at the end of the article
} original author(s) and the source, provide a link to the Creative Commons licence, and indicate if changes were made. The images or other third party material in this article are included in the article's Creative Commons licence, unless indicated otherwise in a credit line to the material. If material is not included in the article's Creative Commons licence and your intended use is not permitted by statutory regulation or exceeds the permitted use, you will need to obtain permission directly from the copyright holder. To view a copy of this licence, visit http://creativecommons.org/licenses/by/4.0/. The Creative Commons Public Domain Dedication waiver (http://creativeco mmons.org/publicdomain/zero/1.0/) applies to the data made available in this article, unless otherwise stated in a credit line to the data. 
Keywords: Slaughterhouse, Abattoir, Kenya, Toxoplasma, Zoonoses, Occupational health

\section{Background}

Toxoplasma gondii is a zoonotic protozoan parasite found worldwide. It infects a wide variety of warmblooded animals including mammals and birds. Sexual reproduction of the parasite occurs in the definitive host (cats) and asexual reproduction occurs in the intermediate hosts (all warm blooded animals) [1]. Infection in people can occur through ingestion of oocysts passed in the faeces of the definitive hosts; ingestion of bradyzoites in the tissue of infected intermediate hosts which is the potential route of transmission to meat handlers including slaughterhouse workers; or exposure to tachyzoites in raw milk and eggs [2]. Vertical transmission is also possible across the placenta [1]. Sporulated oocysts are very robust and can survive in moist soils for more than 12 months [1]. Previously identified risk factors for toxoplasmosis in humans include contact with soil, water or unwashed raw vegetables that might be contaminated with cat faeces, and eating raw meat [2-5].

Toxoplasmosis is generally asymptomatic in immunocompetent individuals but might result in retinitis later in life [6]. Research has also demonstrated a relationship between latent $T$. gondii infection and some mental health disorders [7]. In immunocompromised individuals infection can result in encephalitis with neurological disturbances including seizures and loss of consciousness [8]. Infection in women during early pregnancy can result in foetal death or severe damage to the newborn including, retinochoroiditis, hydrocephalus, seizures and intracerebral calcification [8].

Previously the "gold standard" for definitive diagnosis of T. gondii infection was the Sabin Feldman dye test (SFDT), however ELISAs are now used for routine screening in the majority of laboratories [1]. Although the detection of IgG antibodies using ELISA is likely to be later in the course of infection there is relatively good agreement with the SFDT $[1,9,10]$. IgM antibodies may indicate a more recent exposure, but they can persist for several months to years, which means the presence of IgM antibodies does not indicate acute infection nor the time of exposure [11, 12].

There are few reports of exposure to T. gondii in Kenya. A study of blood donors in several regions of the country showed the seroprevalence to be $54 \%$ [13] and a more recent study of samples collected from women during antenatal clinics in Nairobi, Kisumu and Mombasa reported the prevalence to be $32 \%$ [14]. A more targeted study of school children indicated an increase in seroprevalence between preschool and primary school that might be the result of poor sanitation [15]. Recently a study in slaughterhouses demonstrated the prevalence of $T$. gondii by PCR in ruminant slaughterhouse workers to be $34.6 \%$ and $100 \%$ in chicken slaughterhouse workers [16].

Slaughterhouse workers are considered a high-risk group for $T$. gondii exposure because of their regular contact with raw meat. Although a positive relationship between handling raw meat and T. gondii seropositivity has not been demonstrated in all studies $[17,18]$. The present study aimed to determine the seroprevalence of antibodies to $T$, gondii in slaughterhouse workers in Kenya and identify risk factors associated with seropositivity.

\section{Methods \\ Study site and population}

The study area, in western Kenya on the border with Uganda, is a predominantly rural region characterised by a smallholder mixed crop and livestock system that is broadly representative of the Lake Victoria Basin [19].

A census of all slaughterhouses was attempted with 156 slaughterhouses recruited in the study area -88 ruminant and 68 porcine. Inclusion criteria were all workers aged over 18 years and present at the slaughterhouse on the day of sampling. Participants were excluded for third trimester pregnancy, severe inebriation, and being aged over 85 years.

\section{Ethical approval}

Ethical approval for this study was granted by the Kenya Medical Research Institute Ethical Review Committee (SCC Protocol 2086). The study was conducted in accordance with the Declaration of Helsinki and each participant gave signed informed consent.

\section{Data collection and sampling}

Data collection was conducted between February and November 2012. Data were collected regarding demographic characteristics of the participants, animal contacts, food consumption practices, and time and role in the slaughterhouse. Questionnaire data were recorded on a Palm operating system (Palm OS) Personal digital assistant (PDA) using Pendragon Forms 5.1 (Pendragon Software Corporation, Libertyville, IL). A clinical officer collected blood from each participant using a $21 \mathrm{G}$ or 23G BD Vacutainer ${ }^{\circledR}$ Safetylok ${ }^{\mathrm{TM}}$ blood collection set into $10 \mathrm{ml}$ plain BD Vacutainers ${ }^{\circledR}$. 
The locations of slaughterhouses were georeferenced using a handheld GPS device (Garmin eTrex ${ }^{\circledR}$ ) and mapped using $\operatorname{ArcGIS}^{\mathrm{TM}}$ version 10.2.2 (ESRI, Redlands, California, USA).

\section{Laboratory analysis}

Serum samples were screened with the Vir-ELISA AntiToxo-IgG (Viro-Immun, Oberursel, Germany) and the Vir-ELISA Anti-Toxo-IgM (Immunocaptureassay; ViroImmun, Oberusel, Germany) following manufacturer's instructions. Briefly, the steps for the IgG and IgM ELISAs were: $10 \mu \mathrm{L}$ of sera were diluted in $1 \mathrm{ml}$ of provided diluent and $100 \mu \mathrm{L}$ added to each well of the provided precoated plate. For IgG $100 \mu \mathrm{L}$ of negative control and 4 calibrators were added to the plate and for IgM $100 \mu \mathrm{L}$ of positive and negative control were added. Plates were incubated at $37^{\circ} \mathrm{C}$ for $60 \mathrm{~min}$ in a humid environment. Plates were washed four times and $100 \mu \mathrm{L}$ of peroxidase conjugate added to each well and then incubated at $37^{\circ} \mathrm{C}$ for $30 \mathrm{~min}$ in a humid environment. Plates were washed four times and then $100 \mu \mathrm{L}$ of TMB substrate added to each well and incubated at room temperature $\left(21-25^{\circ} \mathrm{C}\right)$ for $15 \mathrm{~min}$. Finally, $100 \mu \mathrm{L}$ of $0.95 \mathrm{~N}$ sulphuric acid was added to each well and the plates read at $450 \mathrm{~nm}$ (Synergy HT, Biotek, USA).

\section{Statistical analysis}

Statistical analysis was performed in R (http://CRAN.Rproject.org/). The apparent prevalence estimates and the true prevalence estimates were calculated using the truePrev function in the prevalence package [20] of $\mathrm{R}$ accounting for the test sensitivity and specificity reported by the manufacturer of $98.9 \%$ and $100.0 \%$ for the IgG ELISA and $94.3 \%$ and $98.0 \%$ for the IgM ELISA respectively. Design-based adjustment was done with the $s v y$ design procedure in the Survey [21] package in R using sampling weights for each slaughterhouse calculated by dividing the number of expected workers by the number sampled.

Multivariable mixed effects (multi-level) logistic regression models were used to identify risk factors and quantify their association with $T$. gondii seropositivity in slaughterhouse workers. Univariable logistic regression was used to screen variables against $T$. gondii exposure at the individual level. The variables used were those previously reported to be associated with seropositivity to $T$. gondii and included age, gender, contact with livestock, drinking milk, eating meat, role in the slaughterhouse and types of animals slaughtered. All variables are listed in Table 1.

A multivariable mixed effects logistic regression model was developed using variables with a $p$-value $<0.1$ in the univariable analysis. The model was developed using the glmer function in the lme4 package [22] with slaughterhouse included as a random effect to account for clustering of the workers. Model selection was conducted using a backwards stepwise approach starting with a full model containing all predictors. Variables with the highest $p$-value were removed in a stepwise fashion until the model with the lowest Akaike information criterion (AIC) was identified. Variance Inflation Factors (VIF) were calculated from the final model to check for collinearity and variables with VIF $>4$ were excluded.

\section{Results}

The study recruited 738 slaughterhouse workers from 142 ruminant slaughterhouses. Four ruminant slaughterhouses and 10 pig slaughterhouses refused to participate. Serum samples were available from 737 workers; 619 workers were seropositive for IgG antibodies to $T$. gondii with an apparent prevalence of $84.0 \%$ (95\% CI 81.2-86.5\%). The adjusted prevalence estimate accounting for the study design was $84.3 \%$ (95\% CI $81.2-87.4 \%$ ). The true prevalence was $84.8 \%$ (95\% CI 82.1-87.5\%) after adjustment for the sensitivity and specificity of the test. Sixteen (2.2\%; 95\% CI 1.3-3.5\%) workers were positive for IgM antibodies. The adjusted prevalence estimate accounting for the study design was $2.4 \%$ (95\% CI $1.2-$ $3.7 \%)$. The true prevalence was $0.6 \%$ (95\% CI $0-1.8 \%$ ) after adjustment for the sensitivity and specificity of the test. All IgM positive individuals were also IgG positive. The distribution of $T$. gondii seropositive workers through the study area is demonstrated in Fig. 1.

The complete univariable analysis for risk factors for T. gondii IgG seropositivity in slaughterhouse workers included previously reported exposure variables (Table 1). The variables from the univariable analysis significantly associated with $T$. gondii seropositivity in slaughterhouse workers were: age (OR 1.03, 95\% CI 1.01-1.05); owning poultry (OR 1.97, 95\% CI 1.11-3.48); drinking animal blood (OR 1.96 95\% CI 1.26-3.06); and length of time as a slaughterhouse worker (OR 1.04, (95\% CI 1.01-1.07). There was no difference in T. gondii seropositivity between slaughterhouse types (Table 1): with seropositivity of $84.2 \%(230 / 273)$ in cattle, sheep and goat slaughterhouses; $85.3 \%(249 / 292)$ in cattle only slaughterhouses; and $81.3 \%$ (39/171) in pig only slaughterhouses. The univariable analysis was not conducted for IgM seropositivity as the numbers of positive workers was too small.

The final multivariable model for T. gondii IgG seropositivity in individual slaughterhouse workers included the variables gender, age, owning poultry and drinking animal blood. The results are shown in Table 2. Risk factors for exposure to $T$. gondii were: increasing age in years (OR 1.03; 95\% CI 1.01-1.05); owning poultry (OR 2.00; 
Table 1 Results of univariable analysis for risk factors for seropositivity to IgG antibodies to Toxoplasma gondii in slaughterhouse workers from western Kenya

\begin{tabular}{|c|c|c|c|c|}
\hline Variable & Number (\%) n=737 & $\begin{array}{l}\text { Number positive (\%) } \\
n=619\end{array}$ & OR $(95 \% \mathrm{Cl})$ & $p$-value \\
\hline \multicolumn{5}{|l|}{ Individual variables } \\
\hline \multicolumn{5}{|l|}{ Gender } \\
\hline Female & $26(3.5)$ & $18(69.2)$ & 1 & Ref. \\
\hline Male & $711(96.5)$ & $601(84.5)$ & $2.57(0.98-6.72)$ & 0.055 \\
\hline \multicolumn{5}{|l|}{ Age groups } \\
\hline $18-27$ & $167(22.7)$ & $130(77.8)$ & 1 & Ref. \\
\hline $28-37$ & $227(30.8)$ & $186(81.9)$ & $1.42(0.82-2.46)$ & 0.217 \\
\hline $38-47$ & $147(19.9)$ & $127(86.4)$ & $1.95(1.02-3.74)$ & 0.043 \\
\hline $48+$ & $196(26.6)$ & $176(89.8)$ & $2.79(1.46-5.36)$ & 0.002 \\
\hline Age (linear) & & & $1.03(1.01-1.05)$ & 0.001 \\
\hline \multicolumn{5}{|l|}{ Own cattle } \\
\hline No & $252(34.2)$ & $206(81.7)$ & & \\
\hline Yes & $485(65.8)$ & $413(85.2)$ & $1.34(0.86-2.10)$ & 0.196 \\
\hline \multicolumn{5}{|l|}{ Own sheep } \\
\hline No & $624(84.7)$ & $524(84.0)$ & & \\
\hline Yes & $113(15.3)$ & $95(84.1)$ & $1.02(0.56-1.85)$ & 0.947 \\
\hline \multicolumn{5}{|l|}{ Own goats } \\
\hline No & $469(63.6)$ & $391(83.4)$ & & \\
\hline Yes & $268(36.4)$ & $228(85.1)$ & $1.14(0.73-1.80)$ & 0.558 \\
\hline \multicolumn{5}{|l|}{ Own pigs } \\
\hline No & $517(70.1)$ & $429(83.0)$ & & \\
\hline Yes & $220(29.9)$ & $190(86.4)$ & $1.44(0.87-2.36)$ & 0.156 \\
\hline \multicolumn{5}{|l|}{ Own poultry } \\
\hline No & $104(14.1)$ & $80(76.9)$ & & \\
\hline Yes & $633(85.9)$ & $539(85.2)$ & $1.97(1.11-3.48)$ & 0.020 \\
\hline \multicolumn{5}{|l|}{ Drink animal blood } \\
\hline No & $339(46.0)$ & $271(79.9)$ & & \\
\hline Yes & $398(54.0)$ & $348(87.4)$ & $1.96(1.26-3.06)$ & 0.003 \\
\hline \multicolumn{5}{|l|}{ Drink cow's milk } \\
\hline No & $35(4.7)$ & $32(91.4)$ & & \\
\hline Yes & $702(95.3)$ & $587(83.6)$ & $0.43(0.12-1.52)$ & 0.191 \\
\hline \multicolumn{5}{|l|}{ Drink goat's milk } \\
\hline No & $716(97.2)$ & $601(83.9)$ & & \\
\hline Yes & $21(2.8)$ & $18(85.7)$ & $1.02(0.27-3.84)$ & 0.980 \\
\hline \multicolumn{5}{|l|}{ Eat beef } \\
\hline No & $22(3.0)$ & $20(90.9)$ & & \\
\hline Yes & $715(97.0)$ & $599(83.8)$ & $0.58(0.13-2.70)$ & 0.491 \\
\hline \multicolumn{5}{|l|}{ Eat pork } \\
\hline No & $230(31.2)$ & $191(83.0)$ & & \\
\hline Yes & $507(68.8)$ & $428(84.4)$ & $1.18(0.74-1.89)$ & 0.478 \\
\hline \multicolumn{5}{|l|}{ Eat at slaughterhouse } \\
\hline No & $593(80.5)$ & $494(83.3)$ & & \\
\hline Yes & $144(19.5)$ & $125(86.8)$ & $1.18(0.64-2.17)$ & 0.600 \\
\hline \multicolumn{5}{|l|}{ HIV positive } \\
\hline No & $648(87.9)$ & $540(83.3)$ & & \\
\hline Yes & $89(12.1)$ & $79(88.8)$ & $1.65(0.79-3.42)$ & 0.179 \\
\hline \multicolumn{5}{|l|}{ Job in slaughterhouse } \\
\hline Slaughterman/foreman & $79(10.7)$ & $65(82.3)$ & 1 & Ref. \\
\hline
\end{tabular}


Table 1 (continued)

\begin{tabular}{|c|c|c|c|c|}
\hline Variable & Number $(\%) n=737$ & $\begin{array}{l}\text { Number positive (\%) } \\
n=619\end{array}$ & OR $(95 \% \mathrm{Cl})$ & $p$-value \\
\hline Flayer & $579(78.6)$ & $487(84.1)$ & $1.13(0.58-2.18)$ & 0.727 \\
\hline Cleans intestines & $43(5.8)$ & $37(86.0)$ & $1.09(0.36-3.32)$ & 0.880 \\
\hline Cleans slaughterhouse & $36(4.9)$ & $30(83.3)$ & $0.99(0.32-3.05)$ & 0.989 \\
\hline \multicolumn{5}{|l|}{ Other job } \\
\hline No job & $137(18.6)$ & $115(83.9)$ & 1 & Ref. \\
\hline Butcher & $299(40.6)$ & $248(82.9)$ & $0.92(0.51-1.67)$ & 0.784 \\
\hline Farmer & $213(28.9)$ & $182(85.4)$ & $1.04(0.55-1.97)$ & 0.896 \\
\hline Other & $88(11.9)$ & $74(84.1)$ & $0.96(0.44-2.12)$ & 0.927 \\
\hline Time as worker (linear) & & & $1.04(1.01-1.07)$ & 0.019 \\
\hline \multicolumn{5}{|c|}{ Slaughterhouse level variables } \\
\hline \multicolumn{5}{|c|}{ Animal type } \\
\hline Cattle, sheep, goats & $274(37.2)$ & $231(84.3)$ & 1 & Ref. \\
\hline Cattle only & $292(39.6)$ & $249(85.3)$ & $1.18(0.63-2.21)$ & 0.614 \\
\hline Pigs only & $171(23.2)$ & $139(81.3)$ & $0.83(0.43-1.60)$ & 0.574 \\
\hline
\end{tabular}

95\% CI 1.11-3.62); and consuming animal blood (OR $1.92 ; 95 \%$ CI 1.21-3.03).

\section{Discussion}

The apparent seroprevalence of IgG antibodies to T. gondii in slaughterhouse workers in western Kenya was $84.0 \%$ (95\% CI $81.2-86.5 \%)$. This is consistent with reports in slaughterhouse workers in countries from Latin America and Africa, $72 \%$ in Brazil [23], 72\% in Mexico [24] and $55.8 \%$ in Nigeria [25] where the prevalence is reportedly high (>50\%) [1]. This contrasts to Europe where there is low-moderate seroprevalence $(10-50 \%)$ with reports of T. gondii seropositivity in slaughterhouse workers of $45 \%$ [26].

We do not have an estimate of the seroprevalence in the general population in this study area to make a direct comparison, however, the prevalence in slaughterhouse workers is higher than that reported in the community (54\%) in an earlier study conducted in Kenya [13] and a more recent report from western Kenya of $28.2 \%$ [27]. This may indicate that slaughterhouse workers have a higher seroprevalence for antibodies to T. gondii but it we cannot rule out that the difference may also be the result of a different test (ELISA versus haemagglutination and microsphere-based immunoassay), different environments, or another occupational exposure.

A previous study in Kenya demonstrated active infections (PCR positivity) in $34.6 \%$ of ruminant abattoir workers [16]. In our study it was not possible to determine if infections were active since seropositivity for IgM and IgG does not indicate or distinguish between active and chronic infections [11, 12]. The proportion of seropositive workers increased with increasing age as previously reported [1], however, the highest prevalence may be seen in childhood, particularly in areas with poor hygiene, as demonstrated elsewhere in Kenya [15]. Initial exposure to T. gondii occurs in childhood but it is believed that repeated exposure is required to sustain antibody levels [28], which appears to be occurring regularly among slaughterhouse workers in this setting.

There was no relationship between $T$. gondii seropositivity and the role in the slaughterhouse which has previously been identified as a risk factor [23], together with handling meat $[23,29]$. A difference in risk between roles in the slaughterhouse might have been expected since the slaughtermen, foremen and cleaners do not handle meat compared to flayers. However, the lack of differential risk between workers might be explained by the method of batch slaughtering conducted in western Kenya where all processes (skinning, evisceration and cutting) are performed in the same spot without a clear demarcation of activities [30]. Workers may also be involved with slaughtering animals at home, with $15 \%$ of homesteads in the study area reporting home slaughter which may be an additional route of exposure [19]. Further research is required to compare the prevalence and risk factors in the community to determine if handling or consuming meat is a risk factor for slaughterhouse workers.

In our study seropositivity to T. gondii was associated with owning poultry. Poultry are known to be infected with $T$. gondii [31] with the prevalence in backyard chickens reaching $100 \%$ in some settings [32]. In western Kenya poultry are free ranging during the day and are kept in the house or kitchen at night [33], and $87.2 \%$ of households own poultry [19], which is an intensifying industry in the region [34]. Poultry slaughterhouse 


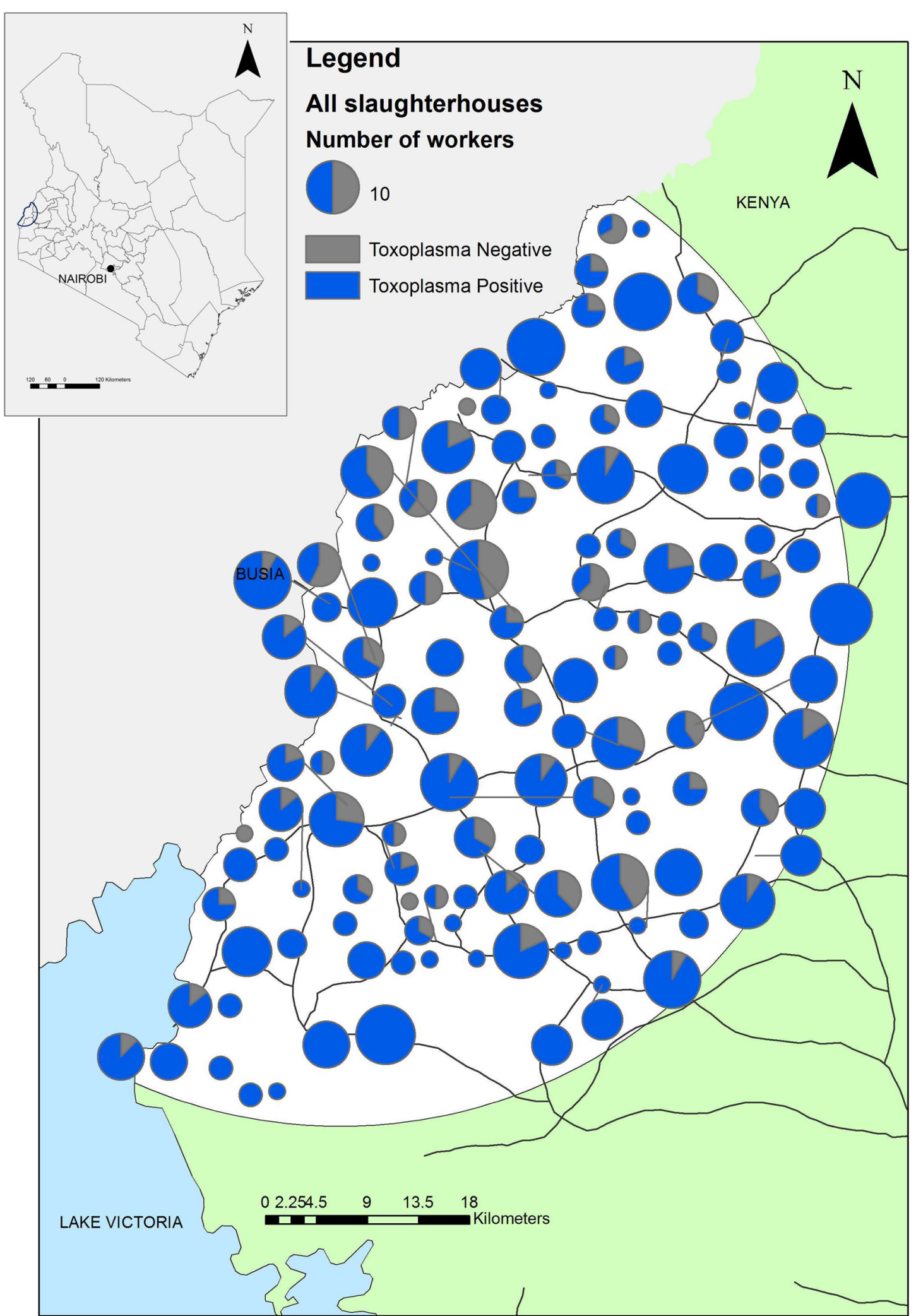

Fig. 1 Map of the distribution of Toxoplasma gondii seropositive and seronegative slaughterhouses. The size of the charts is proportional to the number of workers in each slaughterhouse. This is an original figure created using ArcGIS 
Table 2 Results of the multivariable analysis for lgG antibodies to Toxoplasma gondii in slaughterhouse workers in western Kenya

\begin{tabular}{llll}
\hline Variables & OR $(\mathbf{9 5} \% \mathbf{C l})$ & p-value & VIF \\
\hline Individual variables & & & \\
Male gender & $2.56(0.94-7.00)$ & 0.066 & 1.019 \\
Age & $1.03(1.01-1.05)$ & 0.001 & 1.015 \\
Owning poultry & $2.00(1.11-3.62)$ & 0.022 & 1.023 \\
Drinking animal blood & $1.92(1.21-3.03)$ & 0.005 & 1.003 \\
\hline
\end{tabular}

workers have been shown to have higher risk of being exposed to $T$. gondii $[25,35]$. In this setting poultry are slaughtered at home which may indicate a potential point of exposure for poultry keepers. From the information available it is not possible to determine the potential role of chickens in the epidemiology of T. gondii in this setting but these findings suggest they may be important source of infection and further research is required.

Drinking animal blood was a risk factor for $T$. gondii seropositivity in slaughterhouse workers (OR 1.92; 95\% CI 1.21-3.03). This is consistent with reports that consuming undercooked animal products is a risk factor for exposure to T. gondii [29]. Many workers in this study consume animal blood (54\%) and education regarding the preparation of blood before consumption may reduce the risk of exposure.

Infection with $T$. gondii has previously been associated with severe disease in immunocompromised individuals [36]. The prevalence of HIV in the study area is the highest in Kenya [37]. A significant relationship between $T$. gondii infection and HIV was not identified in this study, and the lack of association may indicate a healthy worker effect [38] with affected individuals unable to work.

\section{Conclusion}

The results of this study indicate a high seroprevalence of antibodies to $T$. gondii in a population of slaughterhouse workers in western Kenya, which suggests repeated exposure. None of the risk factors identified here are specifically associated with working in the slaughterhouse. The high infection pressure identified in this study may signify an unidentified public health risk in this region which is a hazard to vulnerable groups such as people living with HIV or pregnant women. There are some gaps in the information which are required to understand the epidemiology of T. gondii in this setting such as information regarding raw meat consumption and contact with cats. There is currently no data on the disease incidence or mortality from toxoplasmosis in Kenya. In neighbouring Tanzania a 10 year hospital based study reported the mortality from toxoplasmosis to be $0.08 \%(188 / 247,976)$ of the total deaths recorded [39]. A detailed understanding of the epidemiology of infection is required, which needs to include an assessment of incidence, mortality, and burden since congenital T. gondii infection is likely to have life-long sequelae [40]. Future research agendas should consider investing in understanding zoonotic disease risks in sub-Saharan African settings such as this where there is intense animal contact and potential longterm issues.

\section{Abbreviations}

AIC: Akaike information criteria; Cl: Confidence interval; ELISA: Enzyme-linked immunosorbent assay; GPS: Global positioning system; Ig: Immunoglobulin; OR: Odds ratio; PCR: Polymerase chain reaction; PDA: Personal digital assistant; SCC: Scientific Steering Committee; SFDT: Sabin Feldman dye test; VIF: Variance Inflation Factors.

\section{Acknowledgements}

We thank all of the team on the 'PAZ' project for their hard work and diligence We are grateful to all the members of the PAZ field and laboratory teams in Busia in particular Fred Amanya, James Akoko, Lorren Alumasa, Omoto Lazarus, Maseno Cleophas, Daniel Cheruiyot, George Omondi, John Mwaniki, Hannah Kariuki and Lilian Achola. We are grateful to all the participating slaughterhouse workers for their willingness to be involved in the research.

\section{Authors' contributions}

EAJC designed and conducted the data collection and interpretation. NG conducted laboratory analysis and interpretation. EK, EMF, LFT, WAdG and SK assisted with study design and conceptualization. All authors made contributions to conception, design, and revision of the manuscript. All authors read and approved the final manuscript.

\section{Funding}

We thank the Wellcome Trust (085308) for supporting EMF and the People, Animals and their Zoonoses project. Support was also received from the CGIAR Research Program on Agriculture for Nutrition and Health (A4NH), led by the International Food Policy Research Institute (IFPRI). We acknowledge the CGIAR Fund Donors (https://www.cgiar.org/funders/). This work was partfunded by the Global Challenges Research Fund (GCRF) One Health Regional Network for the Horn of Africa (HORN) Project, from UK Research and Innovation (UKRI) and Biotechnology and Biological Sciences Research Council (BBSRC) (project number BB/P027954/1).

\section{Availability of data and materials}

The datasets used and/or analysed during the current study are available from the corresponding author on reasonable request.

\section{Declarations}

\section{Ethics approval and consent to participate}

Ethical approval for this study was granted by the Kenya Medical Research Institute Ethical Review Committee (SCC Protocol 2086). All methods were performed in accordance with the Declaration of Helsinki and each participant gave signed informed consent.

\section{Consent for publication}

Not applicable.

\section{Competing interests}

The authors declare no competing interests..

\section{Author details}

${ }^{1}$ International Livestock Research Institute, Old Naivasha Road, P.O. Box 30709, Nairobi 00100, Kenya. ${ }^{2}$ Institute of Infection Veterinary and Ecological 
Sciences, University of Liverpool, Leahurst Campus, Neston CH64 7TE, UK. ${ }^{3}$ University of Nairobi, P.O. Box 29053, Nairobi 00625, Kenya. ${ }^{4}$ Center for One Health, University of Global Health Equity, Kigali, Rwanda. ${ }^{5}$ Kenya Medical Research Institute, P.O. Box 19464, Nairobi 00200, Kenya.

\section{Received: 26 May 2021 Accepted: 6 September 2021} Published online: 11 September 2021

\section{References}

1. Robert-Gangneux F, Dardé ML. Epidemiology of and diagnostic strategies for toxoplasmosis. Clin Microbiol Rev. 2012. https://doi.org/10.1128/CMR. 05013-11.

2. Tenter AM, Heckeroth AR, Weiss LM. Toxoplasma gondii: From animals to humans. Int J Parasitol. 2000;30(12-13):1217-58.

3. Cook A, Gilbert R, Buffolano W, Zufferey J, Petersen E, Jenum P, et al. Sources of toxoplasma infection in pregnant women: European multicentre case-control study. European Research Network on Congenital Toxoplasmosis. BMJ. 2000;321(7254):142-7.

4. Kapperud G, Jenum P, Sray-Pedersen B, Melby K, Esklin A, Eng J. Risk factors for Toxoplasma gondii infection in pregnancy. Results of a prospective case-control study in Norway. Am J Epidemiol. 1996;144(4):405-12.

5. Baril L, Ancelle T, Goulet V, Thulliez P, Tirard-Fluery V, Carme B. Risk factors for Toxoplasma infection in pregnancy: a case-control study in France. Scand J Infect Dis. 1999;31(3):305-9.

6. Delair E, Monnet D, Grabar S, Dupouy-Camet J, Yera H, Brézin AP. Respective roles of acquired and congenital infections in presumed ocular toxoplasmosis. Am J Ophthalmol. 2008;146(6):851-5.

7. Torrey EF, Yolken RH. Toxoplasma gondii and Schizophrenia. Emerg Infect Dis. 2003:9(11):1375-80.

8. Hill D, Dubey JP. Toxoplasma gondii: Transmission, diagnosis, and prevention. Clin Microbiol Infect. 2002;8(10):634-40.

9. Mondesire R, Charlton D, Tizard I. A standardized enzyme-linked immunosorbent assay (ELISA) for the detection of antibodies to Toxoplasma gondii. J Immunoassay. 1981;2(1):45-57.

10. Ybañez RHD, Ybañez AP, Nishikawa Y. Review on the current trends of toxoplasmosis serodiagnosis in humans. Front Cell Infect Microbiol. 2020;10(May):1-18.

11. Gras L, Gilbert RE, Wallon M, Peyron F, Cortina-Borja M. Duration of the IgM response in women acquiring Toxoplasma gondii during pregnancy: implications for clinical practice and cross-sectional incidence studies. Epidemiol Infect. 2004;132(3):541-8.

12. Liu Q, Wang ZD, Huang SY, Zhu XQ. Diagnosis of toxoplasmosis and typing of Toxoplasma gondii. Parasites Vectors. 2015. https://doi.org/10.1186/ s13071-015-0902-6.

13. Griffin L, Williams KAB. Serological and parasitological survey of blood donors in Kenya for toxoplasmosis. Trans R Soc Trop Med Hyg. 1983;77(6):763-6.

14. Nisbet Al, Omuse G, Revathi G, Adam RD. Seroprevalence data at a private teaching hospital in Kenya: an examination of Toxoplasma gondii, cytomegalovirus, rubella, hepatitis A, and Entamoeba histolytica. PLOS ONE. 2018;13(10):1-11.

15. Bowry T, Camargo M, Kinyanjui M. Sero-epidemiology of Toxoplasma gondii infection in young children in Nairobi, Kenya. Trans R Soc Trop Med Hyg. 1986;80:439-41.

16. Thiongo SK, Ichagichu JM, Ngotho M, Aboge GO, Kagira JM, Karanja $\mathrm{SM}$, et al. Use of the nested polymerase chain reaction for detection of Toxoplasma gondii in slaughterhouse workers in Thika District, Kenya. S Afr Med J. 2016;106(4):417-9.

17. Gonçalves DD, Teles PS, Dos Reis CR, Lopes FMR, Freire RL, Navarro IT, et al. Seroepidemiology and occupational and environmental variables for leptospirosis, brucellosis and toxoplasmosis in slaughterhouse workers in the Paraná State, Brazil. Rev Inst Med Trop Sao Paulo. 2006;48(3):135-40.

18. Alvarado-Esquivel C, Liesenfeld O, Estrada-Martínez S, Félix-Huerta J. Toxoplasma gondii infection in workers occupationally exposed to raw meat. Occup Med. 2011;61(4):265-9

19. Fèvre EM, de Glanville WA, Thomas LF, Cook EAJ, Kariuki S, Wamae CN. An integrated study of human and animal infectious disease in the Lake Victoria crescent small-holder crop-livestock production system Kenya. BMC Infect Dis. 2017. https://doi.org/10.1186/s12879-017-2559-6.
20. Speybroeck N, Devleesschauwer B, Joseph L, Berkvens D. Misclassification errors in prevalence estimation: Bayesian handling with care. Int J Public Health. 2013;58(5):791-95. https://doi.org/10.1007/s00038-012-0439-9.

21. Lumley T. Analysis of complex survey samples. J Stat Softw. 2004;9(1):119. $R$ package verson 2.2.

22. Bates D, Mächler M, Bolker B, Walker S. Fitting Linear Mixed-Effects Models Using Ime4. J Stat Softw. 2015;67(1):1-48. https://doi.org/10.18637/jss. v067.i01.

23. Riemann HP, Brant PC, Behymer DE, Franti CE. Toxoplasma gondii and Coxiella burneti antibodies among Brazilian slaughterhouse employees. Am J Epidemiol. 1975;102(5):386-93.

24. Galván-Ramírez M, Flores Orozco C, Soto MJ. Seroepidemiology of toxoplasma gondii in workers of slaughterhouse in Zapopan, Jalisco. Int J Infect Dis. 2008. https://doi.org/10.1016/j.ijid.2008.05.1014.

25. Ekanem U, Moses A, Abraham E, Motilewa O, Umo A, Itina E. Seroprevalence of anti-toxoplasma gondii igg antibody and risk factors among abattoir workers in Uyo, Southern Nigeria. Niger J Clin Pract. 2018:21:1662-9.

26. Lings S, Lander F, Lebech M. Antimicrobial antibodies in Danish slaughterhouse workers and greenhouse workers. Int Arch Occup Environ Health. 1994;65(6):405-9.

27. Fujii Y, Kaneko S, Nzou SM, Mwau M, Njenga SM, Tanigawa C, et al. Serological surveillance development for tropical infectious diseases using simultaneous microsphere-based multiplex assays and finite mixture models. PLoS Negl Trop Dis. 2014. https://doi.org/10.1371/journal.pntd. 0003040.

28. Rougier S, Montoya JG, Peyron F. Lifelong persistence of toxoplasma cysts: a questionable Dogma? Trends Parasitol. 2017;33(2):93-101. https:// doi.org/10.1016/j.pt.2016.10.007.

29. Jones JL, Dargelas V, Roberts J, Press C, Remington JS, Montoya JG. Risk factors for Toxoplasma gondii infection in the United States. Clin Infect Dis. 2009;49(6):878-84.

30. Cook EAJ, De Glanville WA, Thomas LF, Kariuki S, de Bronsvoort BMC, Fèvre EM. Working conditions and public health risks in slaughterhouses in western Kenya. BMC Public Health. 2017;17(1):1-12.

31. Mose JM, Kagira JM, Karanja SM, Ngotho M, Kamau DM, Njuguna AN, et al. Detection of natural Toxoplasma gondii Infection in chicken in Thika Region of Kenya using nested polymerase chain reaction. Biomed Res Int. 2016;2016:1-5

32. Dubey JP. Toxoplasma gondii infections in chickens (Gallus domesticus): prevalence, clinical disease, diagnosis and public health significance. Zoonoses Public Health. 2010:57(1):60-73.

33. Justus $\mathrm{O}$, Owuor G, Bebe BO. Management practices and challenges in smallholder indigenous chicken production in western Kenya. J Agric Rural Dev Trop Subtrop. 2013;114(1):51-8.

34. Chaiban C, Robinson TP, Fèvre EM, Ogola J, Akoko J, Gilbert M, et al. Early intensification of backyard poultry systems in the tropics: a case study. Animal. 2020;14(11):2387-96.

35. El-Setouhy $M$, Hussein $H$, Abdel Malek $M$. Toxoplasmosis among married female workers in poultiy slaughter houses in Cairo. A cross sectional study. Egypt J Community Med. 1997;15(2):21-6.

36. Basavaraju A. Toxoplasmosis in HIV infection: an overview. Trop Parasitol. 2016:6(2):129-35

37. NASCOP. Preliminary KENPHIA 2018 Report [Internet]. Nairobi; 2020 https://phia.icap.columbia.edu/wp-content/uploads/2020/04/KENPHIA2018_Preliminary-Report_final-web.pdf. Accessed 18 May 2021.

38. Li CY, Sung FC. A review of the healthy worker effect in occupational epidemiology. Occup Med. 1999;49(4):225-9.

39. Mboera LEG, Kishamawe C, Kimario E, Rumisha SF. Mortality patterns of toxoplasmosis and its comorbidities in Tanzania: a 10-year retrospective hospital-based survey. Front Public Health. 2019;7:1-7.

40. Nissen J, Jokelainen P, Stensvold CR, Trevisan C, Fuchs J, Burgdorf KS, et al. The disease burden of congenital toxoplasmosis in Denmark, 2014. PLoS ONE. 2017;12(5):1-12.

\section{Publisher's Note}

Springer Nature remains neutral with regard to jurisdictional claims in published maps and institutional affiliations. 